This item was submitted to Loughborough's Research Repository by the author.

Items in Figshare are protected by copyright, with all rights reserved, unless otherwise indicated.

\title{
Degradation studies of crosslinked polyethylene. 1, Aged in air
}

PLEASE CITE THE PUBLISHED VERSION

https://doi.org/10.1179/174328905X55614

PUBLISHER

(C) Maney Publishing

LICENCE

CC BY-NC-ND 4.0

\section{REPOSITORY RECORD}

Amato, L., Marianne Gilbert, and Andrew Caswell. 2007. "Degradation Studies of Crosslinked Polyethylene. 1, Aged in Air". figshare. https://hdl.handle.net/2134/2996. 
This item was submitted to Loughborough's Institutional Repository by the author and is made available under the following Creative Commons Licence conditions.

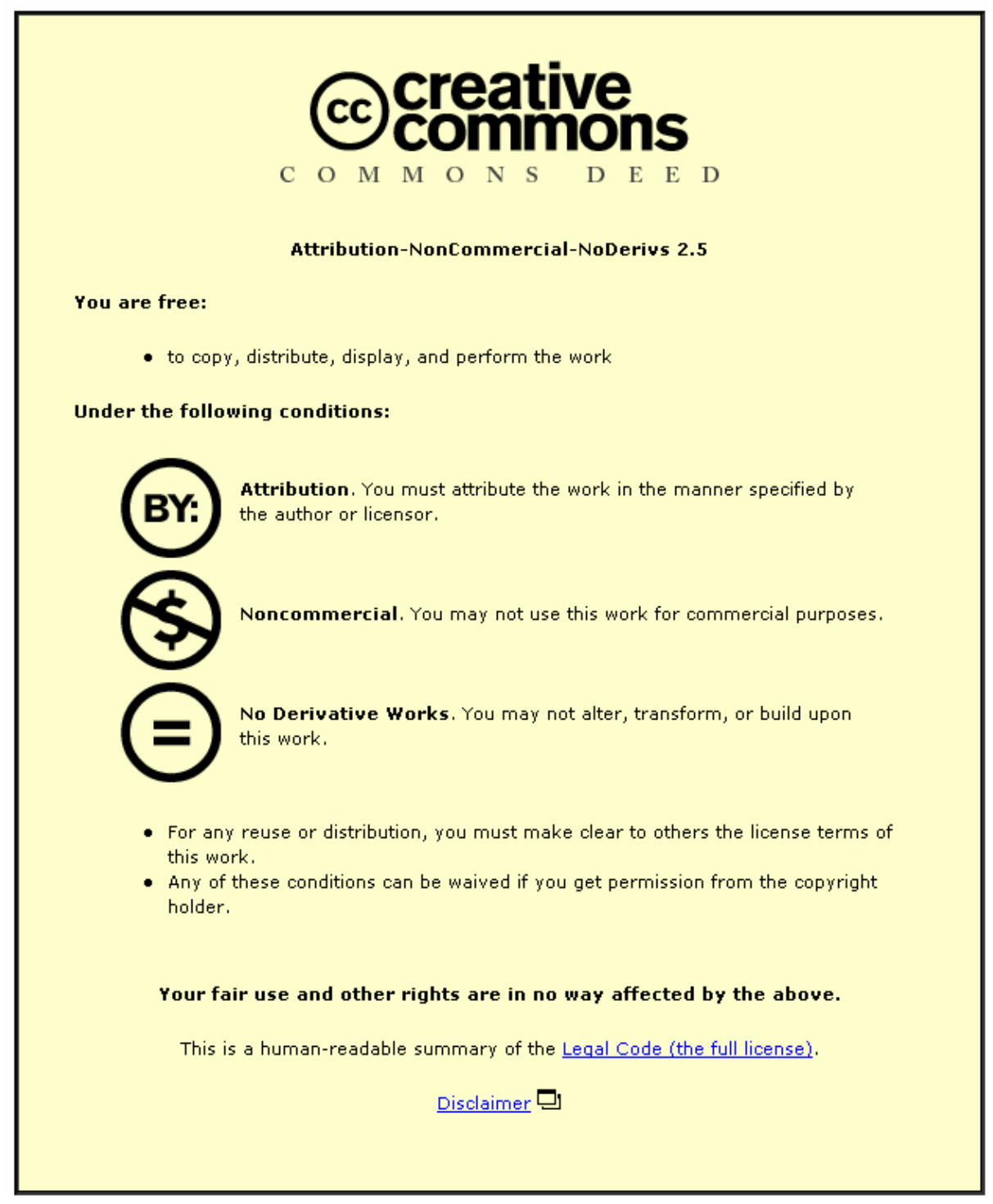

For the full text of this licence, please go to: http://creativecommons.org/licenses/by-nc-nd/2.5/ 


\title{
Degradation Studies of Crosslinked Polyethylene. 1. Aged in air
}

\author{
L. Amato ${ }^{\mathrm{a}}, \mathrm{M}$. Gilbert ${ }^{\mathrm{a}, *}$, A. Caswell ${ }^{\mathrm{b}}$ \\ ${ }^{a}$ Institute of Polymer Technology and Materials Engineering, Loughborough University, LE11 3TU, Loughborough, UK \\ e-mail: L.Amato@lboro.ac.uk; $\underline{\text { M.Gilbert@lboro.ac.uk; }}$ \\ ${ }^{b}$ Wavin Plastics Ltd, Parsonage Way Ind. Est, Chippenham, Wilts., SN15 5PN, UK \\ e-mail: andrew.caswell@wavin.co.uk
}

\begin{abstract}
Silane crosslinking of polyethylene, carried out by grafting an organofunctional silane (vinyltrimethoxysilane) onto polyethylene and by subsequent moisture crosslinking in hot water using a tin catalyst, has been widely used in industrial applications because of its advantages in terms of low cost and easy processing. This study focused on the degradation processes which occurred in the material after air ageing in an oven; temperatures ranged from 90 to $220^{\circ} \mathrm{C}$, while ageing times ranged from $2 \mathrm{~h}$ to $500 \mathrm{~h}$. Significant structural changes were observed according to the different ageing conditions (below and above the melting region of the material), since the carbonyl group concentration increased substantially during ageing above the melting region and the silicone containing groups were also affected by the degradation. These structural changes affected the mechanical and thermal properties of the material, which was annealed at lower ageing temperatures (up to $155^{\circ} \mathrm{C}$ ) and highly degraded at higher temperatures, when C-C crosslinks formed. Experimental design software was used in order to optimise the number of experimental trials and to model the results obtained; its analysis contributed to the interpretation of the results.
\end{abstract}

Keywords: PE-crosslink, air ageing, carbonyl ratio, silane, crystallinity.

\section{Introduction}

Crosslinking reactions are effective in improving some properties of polyethylene: this drastically improves a large number of low-, ambient- and especially high-temperature properties such as heat deformation, abrasion, viscous deformation, chemical and stresscracking resistance, impact and tensile strength, and also adds new properties such as shape memory. 
There are a variety of ways to achieve the crosslinking of polyethylene, which has no functional groups that can provide crosslinking capability, such as those found in typical thermosetting resins, so that the crosslinking must be induced by the incorporation of another component $[1,2]$. The most common method is peroxide crosslinking when peroxide crosslinking agents are added to the resin. A second method of crosslinking polyethylene is through the use of irradiation, such as electron beam irradiation. The third type of crosslinking is through the grafting of a silane onto the polyethylene $[3,4]$ and subsequently through the condensation reaction of the silane graft by moisture (silane crosslinking).

The production of crosslinkable polyethylene through the silane grafting has gained much attention in recent years because of its various advantages such as low cost and capital investment, easy processing, and favourable properties in the processed materials.

The most common silane used in the manufacture of silane crosslinkable polyethylene is vinyl trimethoxysilane (VTMSI), which has conventionally been introduced into polyethylene by melt grafting using a peroxide as an initiator $[3,5]$. The silane-grafted polyolefins are still thermoplastic materials, which are processed in the usual way into finished articles and subsequently subjected to cross-linking in the presence of water. The alkoxy groups hydrolyse to form silanol groups which condense to generate the siloxane bonds responsible for the formation of a three-dimensional network [6-8].

The improvement of thermo-mechanical properties by PE cross-linking [9-11] makes crosslinked polyethylene very attractive for pipes where applications involve elevated temperatures and the transport of chemically aggressive media [12-14]. Uhniat and Kudla [15] carried out a study to evaluate the usefulness of commercial antioxidants in the stabilisation of LDPE crosslinked in the presence of a peroxide and intended for use at high temperatures $\left(100-130^{\circ} \mathrm{C}\right)$. The kinetic study of oxidation was based on the measurement of the oxidation induction time (OIT). It was measured by isothermal differential thermal analysis (DTA) using a DSC scanning mode. The analysis was performed under isothermal conditions in the temperature range 195- 
$225^{\circ} \mathrm{C}$. With phenolic antioxidants a linear relationship exists between the stabilizer concentration and the OIT of polyolefins. Thus, OIT can be used as an analytical method for determining the concentration of sterically hindered phenol [16].

OIT is not however an appropriate method to predict the long-term stability of polyolefins. It can be particularly misleading when used as a screening test to assess the relative performance of stabilizers $[17,18]$. Those industries such as the pipe and wire and cable industry, which have to guarantee their products for 30 to 50 years lifetime, have specified OIT for quality purposes and screening tests. The validity of the method as an accelerated test to predict behaviour at normal temperatures has always been questioned; extensive studies done with polyolefins for cable insulation have shown that the extrapolation of DSC/DTA OIT data leads to considerable overestimation of lifetime compared with data deduced from oven ageing in an air oven [19]. Experience has shown that the OIT response is a function of the antioxidant used; the differences in stabilizing efficiency as determined by OIT are related to the chemical structure of additives.

In this study silane crosslinked polyethylene used for pipe applications was oven aged; several characterization techniques were used to understand the properties of the material after ageing and oxidation, which were correlated with the structural changes occurring during the degradation process. In a related study crosslinked polyethylene was aged in water, these results are presented in a separate paper [20].

\section{Experimental}

Strips $(17.5 \mathrm{~cm} \times 2.7 \mathrm{~cm} \times 1.5 \mathrm{~mm})$ of silane-grafted polyethylene (ISOPLAS P471+P512/CMB) supplied by MICROPOL Ltd were used for the experimental work: P471 is the graft copolymer made by extrusion compounding, while P512 is the catalyst masterbatch. The material contains a mix of three different antioxidants supplied by CIBA Ltd: a phenolic one acting as a primary 
antioxidant and two phosphites acting as secondary antioxidants according to a synergistic mechanism of action.

The samples were conditioned in water at different temperatures and different times in order to obtain a set of crosslinked samples with a range of different gel contents. Conditioning temperature ranged from room temperature to $90^{\circ} \mathrm{C}$, while conditioning time ranged from $1 \mathrm{~h}$ up to $100 \mathrm{~h}$. Air ageing experiments on silane crosslinked polyethylene were then carried out in a fan oven (Gallenkamp BS Oven 250). The ageing temperature ranged from $90^{\circ} \mathrm{C}$ and $220^{\circ} \mathrm{C}$ while the ageing time ranged from $2 \mathrm{~h}$ to $500 \mathrm{~h}$. ECHIP software for experimental design was used in order to optimise the number of experimental trials to be performed and to model the experimental results obtained. A partial cubic model with two inputs (ageing time and ageing temperature) and three outputs (carbonyl ratio, percentage crystallinity and yield strength) seemed to be the most appropriate to fit the results.

Solvent extraction in boiling xylene was used to measure the percentage crosslinking in the samples. About $0.2 \mathrm{~g}$ were cut from crosslinked polyethylene strips and immersed in $100 \mathrm{ml}$ of xylene; the system was refluxed for 19h. After ageing, the samples were refluxed again in boiling xylene, in order to measure the gel content.

Air aged samples were then characterized by using a FTIR spectrometer MATTSON 3000 in order to examine the chemical changes occurring during ageing and oxidation and to monitor the increase of $\mathrm{C}=\mathrm{O}$ group concentration as a measurement of the extent of oxidation in the samples. $50 \mu \mathrm{m}$ thick films were produced by the use of a microtome, then placed between two sodium chloride discs for the analysis which was carried out in the absorbance mode in the frequency range between $4000-400 \mathrm{~cm}^{-1}$.

A Differential Scanning Calorimeter 2010 supplied by TA Instruments was used to investigate the melting and crystallization behaviour of the aged samples and to monitor any significant changes in the percentage crystallinity; after ageing, the samples were taken out of the oven and immediately analysed by DSC analysis. Samples of about $10 \mathrm{mg}$ were heated up to $170^{\circ} \mathrm{C}$ at a 
rate of $10^{\circ} \mathrm{C} / \mathrm{min}$, then cooled down to $30^{\circ} \mathrm{C}$ at $10^{\circ} \mathrm{C} / \mathrm{min}$ and reheated up to $170^{\circ} \mathrm{C}$ at the same rate, the tests being performed in a nitrogen flow of $50 \mathrm{~cm}^{3} / \mathrm{min}$. A value of $277.6 \mathrm{~J} / \mathrm{g}$ was used for the enthalpy of fusion of pure crystalline polyethylene [21].

A set of tensile tests at room temperature on the aged samples was performed using a Hounsfield testing machine: small dumbbells $10 \mathrm{~mm}$ long, $2.4 \mathrm{~mm}$ wide and $1.57 \mathrm{~mm}$ thick were cut and a load cell of $100 \mathrm{~N}$ and a crosshead speed of $100 \mathrm{~mm} / \mathrm{min}$ were used for the analysis.

Samples before and after ageing were observed using a ZEISS Universal optical microscope with polarized and ordinary light in order to observe how the ageing and degradation process affected the microstructure in the samples; the system was connected to a camera with software for the acquisition and analysis of images.

\section{Results}

Solvent extraction

Some results of extraction in boiling xylene carried out on aged crosslinked samples are shown in Table 1; it seems that all the samples aged in air have very high values of gel content, ranging from $76 \%$ for samples aged at $133^{\circ} \mathrm{C}$ for $2 \mathrm{~h}$ to $91 \%$ for samples aged at $220^{\circ} \mathrm{C}$ for $500 \mathrm{~h}$; the initial values of gel contents for these samples before ageing were 72-76 \%.

\section{FTIR experiments}

The set of ageing experiments suggested by the ECHIP software is shown in Table 2; ageing temperatures ranged from 90 to $220^{\circ} \mathrm{C}$ while ageing time ranged from $2 \mathrm{~h}$ to $500 \mathrm{~h}$; some trials were repeated for consistency. 
Significant changes were observed in the FTIR spectra during ageing in the region where the silicone groups absorb (between $800-1200 \mathrm{~cm}^{-1}$ ) and in the region of the carbonyl group (about $\left.1700 \mathrm{~cm}^{-1}\right)$.

The carbonyl ratio was calculated as the ratio between the area of the carbonyl peak and the area of the double peak at about $2920 \mathrm{~cm}^{-1}$ and $2850 \mathrm{~cm}^{-1}$ attributed respectively to the asymmetrical and symmetrical stretching of $\mathrm{CH}_{2}$ group, and used as a reference peak.

Fig.1 compares the FTIR spectra for unaged crosslinked polyethylene and for crosslinked polyethylene aged in air at $150^{\circ} \mathrm{C}$ for 53 days. The region where the $\mathrm{C}=\mathrm{O}$ group absorbs shows a high multiple peak between $1700-1800 \mathrm{~cm}^{-1}$ after ageing. Three different peaks are observed at 1720, 1740 and $1780 \mathrm{~cm}^{-1}$ respectively. An expanded spectrum, fig. 2 shows that for an unaged crosslinked sample there is initially one sharp peak at $1091 \mathrm{~cm}^{-1}$ attributed to the Si-O-Si bonds which form due to condensation of the silanol groups [22-24] and one peak at about $1191 \mathrm{~cm}^{-1}$, attributed to $\mathrm{Si}-\mathrm{O}-\mathrm{CH}_{3}$ bonds due to silane grafting. Fig. 3 shows that the region of the spectrum where the silicone groups absorb $\left(800-1300 \mathrm{~cm}^{-1}\right)$ changed significantly after ageing the samples in the oven at $220^{\circ} \mathrm{C}$ for $500 \mathrm{~h}$. The shape of the FTIR spectrum between $1000-1300 \mathrm{~cm}^{-1}$ changes significantly after ageing the samples at $220^{\circ} \mathrm{C}$ up to $500 \mathrm{~h}$ in the oven, as additional peaks at frequencies of 1021, 1051, 1072, $1109 \mathrm{~cm}^{-1}$ attributed to different structures forming during the ageing process are observed.

\section{DSC experiments}

DSC experiments were carried out on the air aged samples to understand their melting and crystallization behaviour; the samples were heated at $10^{\circ} \mathrm{C} / \mathrm{min}$ up to $170^{\circ} \mathrm{C}$, then cooled down to $30^{\circ} \mathrm{C}$ at $10^{\circ} \mathrm{C} / \mathrm{min}$ and finally reheated up to $170^{\circ} \mathrm{C}$ at the same heating rate. The second heating cycle was carried out in order to eliminate any thermal history; percentage crystallinity was therefore calculated from the enthalpy of fusion values obtained after the second heating. Fig.4 shows the DSC results obtained for samples aged at $90^{\circ} \mathrm{C}$ for $251 \mathrm{~h}$. Fig. 5 shows the DSC 
results for samples aged at $220^{\circ} \mathrm{C}$ for $22 \mathrm{~h}$ : a very low value of percentage crystallinity was obtained, while their melting and crystallization temperatures also decreased compared with the values obtained for unaged crosslinked polyethylene.

\section{Variation of $\mathrm{C}=\mathrm{O}$ ratio and percentage crystallinity with ageing conditions}

Fig. $6 a$ and $6 b$ show how the carbonyl ratio changes with ageing temperature and ageing time. The carbonyl ratio has an initial value of about 0.013 , then it increases with ageing temperature for an ageing time of $500 \mathrm{~h}$, up to a value of 0.14 for samples aged at $220^{\circ} \mathrm{C}$. Fig. 7 shows that for the same time (500h) percentage crystallinity initially increases with ageing temperature reaching a maximum value of $68 \%$ at $155^{\circ} \mathrm{C}$, then it decreases significantly to about $25 \%$ at $220^{\circ} \mathrm{C}$. Fig. 8 a shows that for samples aged for $500 \mathrm{~h}$ percentage crystallinity increases with ageing temperature from $57 \%$ to $66 \%$; fig. $8 \mathrm{~b}$ shows that during ageing at $220^{\circ} \mathrm{C}$, crystallinity decreases with ageing time from an initial value of $57 \%$ to a value of about $25 \%$ after ageing for $500 \mathrm{~h}$

Fig.9a shows the experimental conditions at which percentage crystallinity is minimum (ageing $\mathrm{T}=220^{\circ} \mathrm{C}$, ageing time $=375 \mathrm{~h}$ ); fig.9b shows the conditions at which the carbonyl ratio reaches its maximum value (ageing temperature $=220^{\circ} \mathrm{C}$, ageing time $=298 \mathrm{~h}$ ).

\section{Tensile tests}

A set of tensile tests was carried out on the aged samples in order to investigate how the elongation at break at room temperature is affected by the ageing process; results are shown in fig. 10 and table 3.

On increasing the ageing temperature from 90 to $220^{\circ} \mathrm{C}$ there are significant changes in the shape of the tensile curve, elongation at break at room temperature decreases from $565 \%$ for samples aged at $90^{\circ} \mathrm{C}$ for $500 \mathrm{~h}$ to a value of $11.5 \%$ for samples aged at $220^{\circ} \mathrm{C}$ for $500 \mathrm{~h}$. The 
value of yield strength also decreases from $21.8 \mathrm{MPa}$ for samples aged at $90^{\circ} \mathrm{C}$ for $500 \mathrm{~h}$ to 10.8 MPa for samples aged at $220^{\circ} \mathrm{C}$ for the same time.

\section{Optical microscopy}

The microstructures of some air aged samples were observed using an optical microscope; fig. 11 shows the microstructure of a sample aged at $220^{\circ} \mathrm{C}$ for $334 \mathrm{~h}$.

\section{Discussion}

In order to assess the durability and the performances of the material at elevated temperatures, different techniques were used to characterize samples aged in air for different ageing times and temperatures; comparing the two FTIR spectra shown in fig. 1, it is possible to notice significant changes as the ageing proceeds. The region of the spectrum between $800-1300 \mathrm{~cm}^{-1}$ changes substantially: initially (fig.2) there is one peak at $1090 \mathrm{~cm}^{-1}$, attributed to siloxane bonds in open structures (Si-O-Si) [22-24] which form due to condensation of the silanol groups and one peak at about $1190 \mathrm{~cm}^{-1}$, attributed to $\mathrm{Si}-\mathrm{O}-\mathrm{CH}_{3}$ bonds due to silane grafting. After ageing at $220^{\circ} \mathrm{C}$ for 500h (fig.3), significant changes in this region of the spectrum are observed, as more peaks form at intermediate frequencies between 1090 and $1020 \mathrm{~cm}^{-1}$, attributed to siloxane bonds in cyclic structures, e.g. five or six membered rings [22]. The region of the spectrum concerning the carbonyl group also changes significantly during air ageing and oxidation. Initially for the unaged samples the peak at about $1740 \mathrm{~cm}^{-1}$ is barely visible (fig.1), as the only carbonyl groups present as ester originate from the phenolic antioxidant, which is present at low concentrations. During ageing at $150^{\circ} \mathrm{C}$ (fig.1) this peak starts to split into more peaks and its area increases: the peak at about $1720 \mathrm{~cm}^{-1}$ is attributed to $\mathrm{C}=\mathrm{O}$ of a ketone forming as the initial stage of oxidation through a radical mechanism via a hydroperoxide precursor [24]. Hydroperoxides are formed 
during oxidation of polyolefins. These subsequently decompose by a free-radical mode to produce carbonyl and hydroxyl compounds (equation (1)).

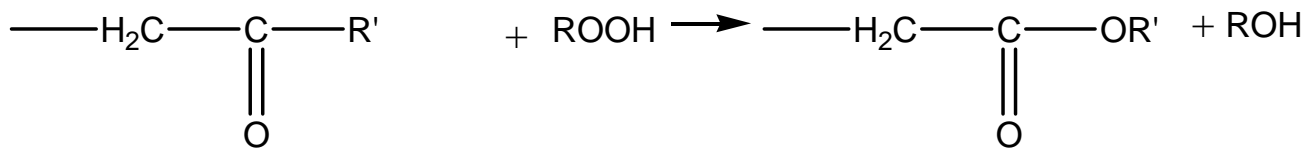

The peak at about $1740 \mathrm{~cm}^{-1}$ shown in fig. 1 is attributed to a vinyl ester structure $[23,24]$ as the oxidation proceeds and finally the peak at about $1780 \mathrm{~cm}^{-1}$, which can be observed for samples aged at $150^{\circ} \mathrm{C}$ for 53 days, is attributed to acid or anhydride structures produced at the final stage of oxidation process [23,25]. These structures can undergo decarboxylation as oxidation proceeds: different mechanisms have been proposed [26-28] (equation (2)).

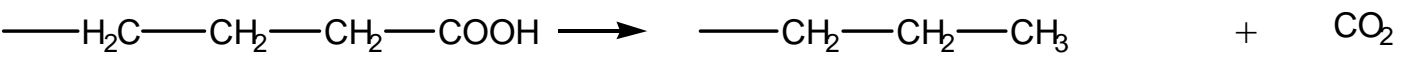

On ageing at temperatures in the melting range of the material $\left(90-150^{\circ} \mathrm{C}\right)$, the system is still semicrystalline; the presence of residual crystals slows the oxygen diffusion into the amorphous phase down, therefore at these temperatures there is not much oxidation, as shown by FTIR analysis, where carbonyl ratio starts to increase after ageing in air at $150^{\circ} \mathrm{C}$ for long times. From the DSC analysis carried out on samples aged in air at low ageing temperatures (90$155^{\circ} \mathrm{C}$ ), percentage crystallinity in the samples is still quite high (about 55\%) and it increases with the ageing time up to $68 \%$ after 500h, as an annealing process occurs (fig.4); there are no significant changes in melting and crystallization temperatures compared with the values obtained for unaged crosslinked polyethylene $\left(T_{m}\right.$ is about $130^{\circ} \mathrm{C}$ while $T_{c}$ is about $\left.113^{\circ} \mathrm{C}\right)$. It seems that ageing in air of PEX samples causes C-C crosslinking, since the gel content of the samples increases significantly after ageing at high temperatures for long times (from about $75 \%$ to $90 \%$ ) as shown in table 1 . 
On ageing at temperatures above the melting range of the material $\left(150-220^{\circ} \mathrm{C}\right)$, the system is mainly amorphous therefore the oxygen diffusion is accelerated, favoured also by the high temperatures. DSC tests carried out on samples aged at high temperatures showed that percentage crystallinity and melting and crystallization temperatures decrease significantly (fig.5). Percentage crystallinity decreases because the regular structure is disrupted by the presence of carbonyl groups and C-C crosslinks, since oxidation causes crosslinking. Melting and crystallization temperatures decrease because the crystals which are formed in these conditions have a less regular structure, characterized by surface defects.

The structural differences among samples aged in air at different conditions affect their mechanical properties as observed from the results obtained by performing some tensile tests, where samples aged at low ageing temperatures $\left(90-157^{\circ} \mathrm{C}\right)$ show a ductile fracture (fig. 10a) and higher values of elongation at break at room temperature (table 3), similar to the values obtained for unaged crosslinked polyethylene (about 600\%); samples aged at high temperatures $\left(157-220^{\circ} \mathrm{C}\right)$ show a much more brittle fracture (fig. 10b) and significantly lower values of yield strength and elongation at break. This different behaviour is attributed to the different structure of the material; above the melting region, the system is mainly amorphous and the yield strength of the material decreases as crystallinity decreases; elongation at break decreases due to the increase of C-C crosslinking, which prevents the mobility of chains.

The graphs shown in figs 6-8 are the variations of the outputs of the model with the ageing conditions; figs 6a, $6 \mathrm{~b}$ and $8 \mathrm{a}$ show both the experimental results and the predicted values of the outputs carbonyl ratio and percentage crystallinity, obtained by using ECHIP for certain ageing conditions; the model chosen seems to fit the experimental results quite consistently. ECHIP analysis of the experimental results obtained, highlighted the ageing conditions at which the outputs of the model reach extreme values (figs 9a and 9b). 
The micrograph in fig. 11 confirms that the sample aged in air at $220^{\circ} \mathrm{C}$ for $334 \mathrm{~h}$ is highly degraded. Its texture is very fine and cracks can be observed at the edge due to the oxidation process.

\section{Conclusions}

This study performed on air aged silane crosslinked polyethylene highlighted the significant structural changes occurring in the material during the ageing process. At ageing temperatures below the melting point of the material, degradation was not significant and an annealing process occurred, therefore the material still had a ductile behaviour and high values of elongation at break. At ageing temperatures above the melting region, there was a substantial increase in carbonyl concentration and the type of carbonyl containing groups also changed, as a result of the degradation process. Significant changes were also observed in the region where silicone groups absorb, as additional structures such as cyclic siloxane bonds were formed. Simultaneous changes in melting, crystallization behaviour and mechanical properties were observed and a good interpretation of the experimental results was achieved by using the ECHIP software which helped to minimize the number of experimental trials and to correlate the response of the material to the different ageing conditions.

\section{Acknowledgements}

The authors would like to thank Wavin Industrial Products for the support provided to this work. 


\section{References}

1. S. Al-Malaika: 'Reactive modifiers for polymers'; 1997, London, Blackie Academic \& Professional.

2. 'The Invention of Chemically Crosslinked Polyethylene': IEEE Electrical Insulation Magazine, 1999; 51, 23-25.

3. M.P. Munoz, M.D.Vargas, M.M. Werlang, R.S. Mauler: Journal of Applied Polymer Science, 2001, 82, 3460.

4. H.G. Scott: 'Grafting and Crosslinking of Polymers with Alkoxy Silanes': U.S. Patent 3, 646,155.

5. Y.T. Shieh, J.S. Liau, T.K. Chen: Journal of Applied Polymer Science, 2001, 81, 186.

6. T. Hjertberg, M. Palmlof, B.A. Sultan: Journal of Applied Polymer Science, 1991, 42, 1185-1192.

7. T. Hjertberg, M. Palmlof, B.A. Sultan: Journal of Applied Polymer Science 1991, 42, 1193-1203.

8. V.S. Osipchik, E.D. Lebedeva, L.G. Vasilets: International Polymer Science and Technology, 2001, 28, 72.

9. J.F. Kuan, L. Chi-Tu, K. Wang, J. Huang: ANTEC, 2001, 3583.

10. Y.T. Shieh, K.I. Hsiao: Journal of Applied Polymer Science, 1998, 70, 1075.

11. M. Narkis, A. Tzur: Polymer Engineering and Science, 1985, 25, 857.

12. T.R. Manley, M.M. Qayyum: Polymer, 1972, 13, 587.

13. S.O. Han, D.W. Lee, O.H. Han: Polymer Degradation and Stability, 1999, 63, 237.

14. M. Celina, M.A. George: Polymer Degradation and Stability, 1995, 48, 297.

15. M. Uhniat, S. Kudla: Polymer Degradation and Stability, 2001, 71, 69.

16. K. Nagy, E. Epacher, P. Staniek: Polymer Degradation and Stability, 2003, 82, 211-219.

17. Th. Schmutz, E. Kramer, H. Zweifel: Ciba-Geigy Ltd., Basel, Switzerland, 2000.

18. L. Ahlstrand: Proceedings Plastics Pipes IX, International Conference, Edinburgh, Scotland, 18-21 September 1995, Heriot-Watt University.

19. J.R. Pauquet, R.V. Todesco, W.O. Drake: Ciba-Geigy Ltd., Basel, Switzerland, 1993.

20. L.Amato, M.Gilbert, A.Caswell: Plastics, Rubber \& Composites: Macromolecular Engineering, March 2005.

21. J. Brandup, E.H. Immergut: 'Polymer Handbook', Vol.16-17, 1989, Wiley, New York.

22. A. Lee Smith: Spectrochimica Acta, 1960, 16, 87-105.

23. A.L. Smith: 'Analysis of Silicones', Vol. 41, 247, 1974, John Wiley \& Sons, US.

24. L. Bellamy: 'Advances in Infrared Group Frequencies', 1968, The Chaucer Press Ltd, UK.

25. R.M. Silverstein, G.C. Bassler, T.C. Morrill: 'Spectrometric Identification of Organic Compounds', $5^{\text {th }}$ edn, 1991, John Wiley \& Sons, Inc, US.

26. R. Broska, J. Rychly: Polymer Degradation and Stability, 2001, 72, 271-278.

27. F. Gugumus: Polymer Degradation and Stability, 2002, 76, 329-340.

28. J. March: 'Advanced Organic Chemistry', $4^{\text {th }}$ edn, 1992, John Wiley \& Sons, US.

29. N.Grassie, G. Scott: 'Polymer Degradation \& Stabilisation', 1985, Cambridge University Press, Cambridge, UK. 


\section{Figure captions}

Fig.1 FTIR spectra of crosslinked polyethylene before ageing and after ageing at $150^{\circ} \mathrm{C}$ for 53 days

Fig.2 FTIR spectrum for crosslinked polyethylene from $800-1300 \mathrm{~cm}^{-1}$ before ageing

Fig.3 FTIR spectrum of sample aged at $220^{\circ} \mathrm{C}$ for $500 \mathrm{~h}\left(800-1300 \mathrm{~cm}^{-1}\right)$

Fig.4 DSC trace of a sample aged at $90^{\circ} \mathrm{C}$ for $251 \mathrm{~h}$

Fig.5 DSC trace of a sample aged at $220^{\circ} \mathrm{C}$ for $22 \mathrm{~h}$

Fig.6a Variation of carbonyl ratio with ageing temperature (ageing time 500h)

Fig.6b Variation of carbonyl ratio with ageing time (ageing temperature $220^{\circ} \mathrm{C}$ )

Fig.7 Variation of crystallinity with ageing temperature (ageing time 500h)

Fig.8a Variation of crystallinity with ageing time (ageing temperature $90^{\circ} \mathrm{C}$ )

Fig.8b Variation of crystallinity with ageing time (ageing temperature $220^{\circ} \mathrm{C}$ )

Fig.9a ECHIP analysis of ageing results: minimum crystallinity

Fig.9b ECHIP analysis of ageing results: maximum carbonyl ratio

Fig.10a Stress-strain curve for samples aged at $90^{\circ} \mathrm{C}$ for $500 \mathrm{~h}$

Fig.10b Stress-strain curve for samples aged at $220^{\circ} \mathrm{C}$ for $500 \mathrm{~h}$

Fig.11 Microstructure of a sample aged in air at $220^{\circ} \mathrm{C}$ for $334 \mathrm{~h}$ 
Table 1 Gel content of air aged samples

\begin{tabular}{|c|c|c|}
\hline Ageing T ( $\left.{ }^{\circ} \mathbf{C}\right)$ & Ageing time (h) & Gel content (\%) \\
\hline 133 & 2 & 76 \\
\hline 90 & 251 & 77 \\
\hline 176 & 2 & 78 \\
\hline 155 & 500 & 80 \\
\hline 220 & 334 & 90 \\
\hline 220 & 500 & 91 \\
\hline
\end{tabular}

Table 2 Set of experimental trials suggested by the ECHIP software

\begin{tabular}{|c|c|c|c|c|c|}
\hline Trials & Ageing T $\left({ }^{\circ} \mathbf{C}\right)$ & Ageing time (h) & $\mathbf{C}=\mathbf{O}$ ratio & \%Cryst. & Yield strength (MPa) \\
\hline 1 & 90 & 500 & 0.016 & 64.0 & 21.8 \\
\hline 2 & 90 & 500 & 0.015 & 68.0 & 18.0 \\
\hline 3 & 90 & 251 & 0.019 & 55.0 & 22.3 \\
\hline 4 & 90 & 251 & 0.038 & 62.0 & 18.5 \\
\hline 5 & 155 & 500 & 0.060 & 59.0 & 19.6 \\
\hline 6 & 155 & 500 & 0.048 & 69.0 & 19.8 \\
\hline 7 & 220 & 500 & 0.115 & 22.2 & 10.8 \\
\hline 8 & 220 & 500 & 0.140 & 31.0 & 10.0 \\
\hline 9 & 220 & 2 & 0.041 & 58.0 & 19.3 \\
\hline 10 & 220 & 2 & 0.035 & 57.7 & 17.5 \\
\hline 11 & 90 & 2 & 0.016 & 57.1 & 22.3 \\
\hline 12 & 176 & 2 & 0.013 & 56.7 & 17.0 \\
\hline 13 & 133 & 2 & 0.050 & 57.7 & 17.3 \\
\hline 14 & 220 & 168 & 0.191 & 32.0 & 11.9 \\
\hline 15 & 220 & 334 & 0.211 & 25.4 & 10.9 \\
\hline 16 & 133 & 334 & 0.031 & 67.7 & 19.3 \\
\hline
\end{tabular}


Table 3 Tensile data for samples aged for $500 \mathrm{~h}$ and samples aged at $220^{\circ} \mathrm{C}$ for different times

\begin{tabular}{|c|c|c|}
\hline Ageing conditions & Yield strength (MPa) & Elongation at break (\%) \\
\hline $90^{\circ} \mathrm{C}-500 \mathrm{~h}$ & 21.8 & 565 \\
\hline $155^{\circ} \mathrm{C}-500 \mathrm{~h}$ & 19.6 & 400 \\
\hline $220^{\circ} \mathrm{C}-500 \mathrm{~h}$ & 10.8 & 11 \\
\hline $220^{\circ} \mathrm{C}-168 \mathrm{~h}$ & 43.3 & 17 \\
\hline $220^{\circ} \mathrm{C}-334 \mathrm{~h}$ & 42.8 & 14 \\
\hline $220^{\circ} \mathrm{C}-500 \mathrm{~h}$ & 10.8 & 11 \\
\hline
\end{tabular}

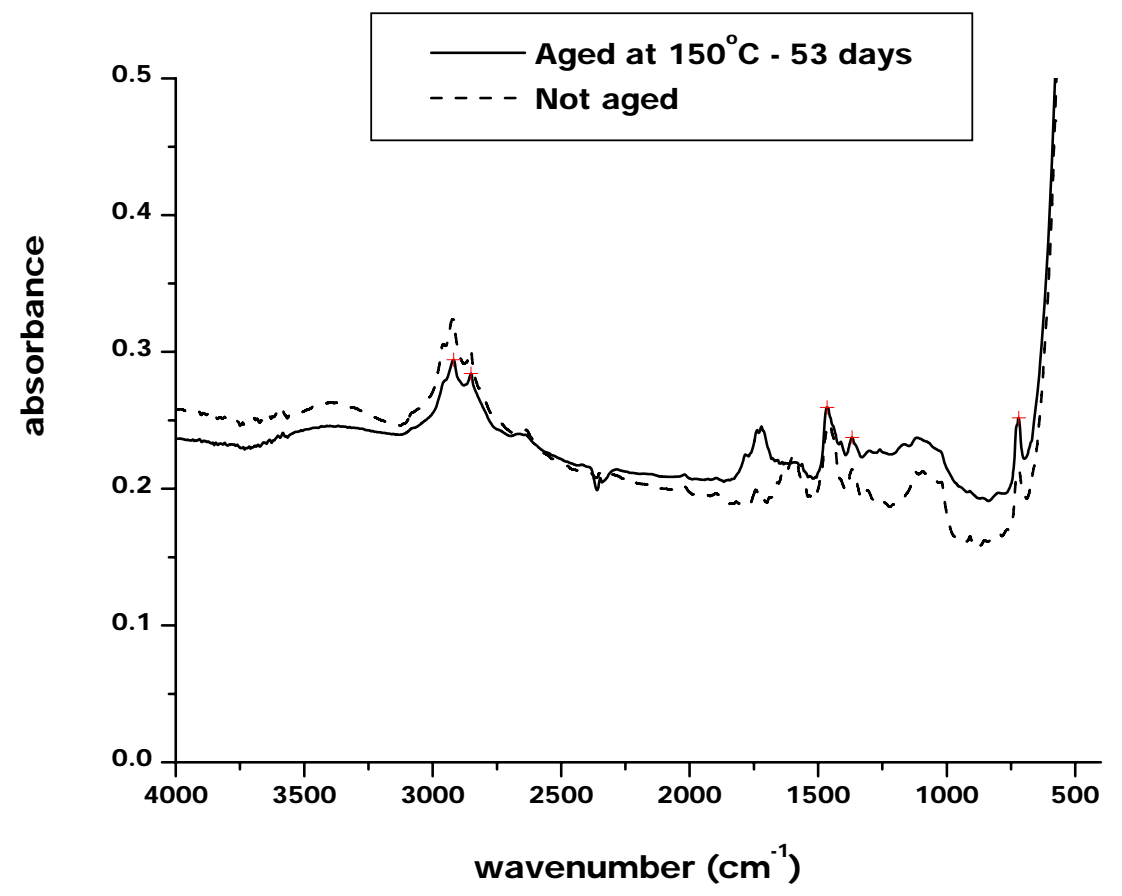

Fig. 1 


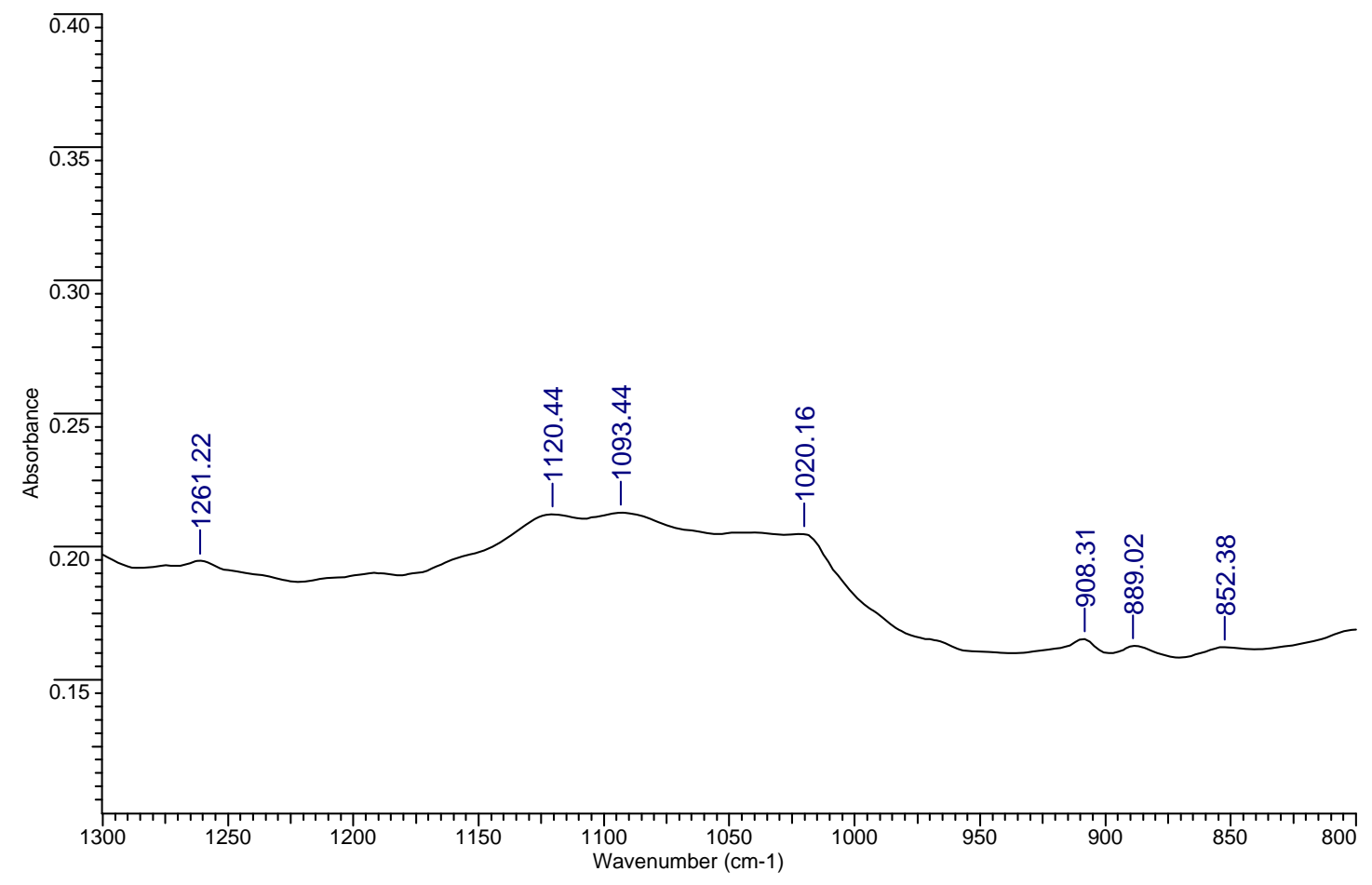

Fig. 2 


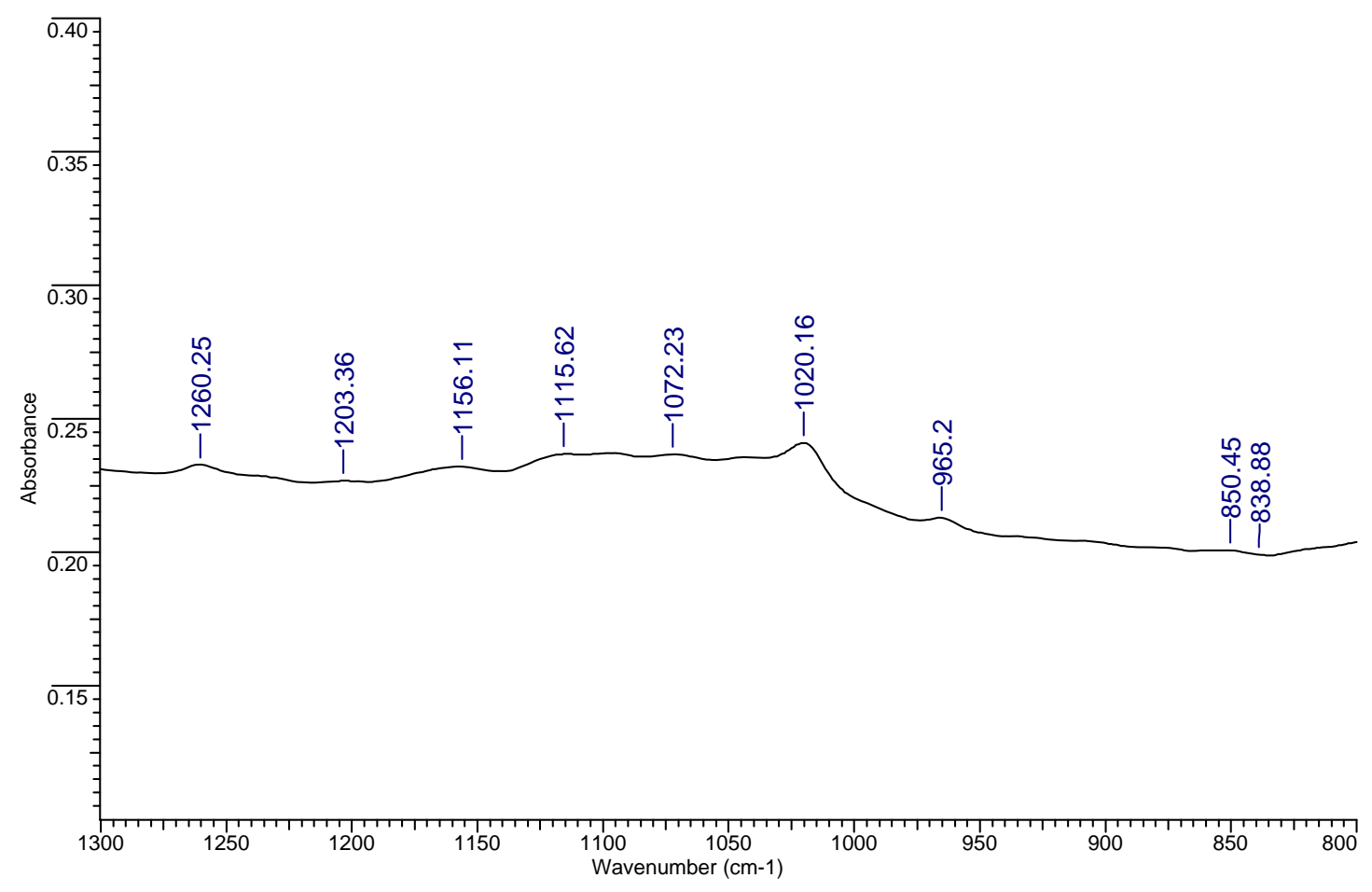

Fig. 3 
Sample: sample air aged $90 \mathrm{C}-251 \mathrm{H}$

Size: $10.0000 \mathrm{mg}$

DSC

File: A:lairag $90-251 \mathrm{H}$

Operator: LA

Run Date: 8-Dec-03 11:18

Comment: 10C/min

Instrument: 2010 DSC V4.4E

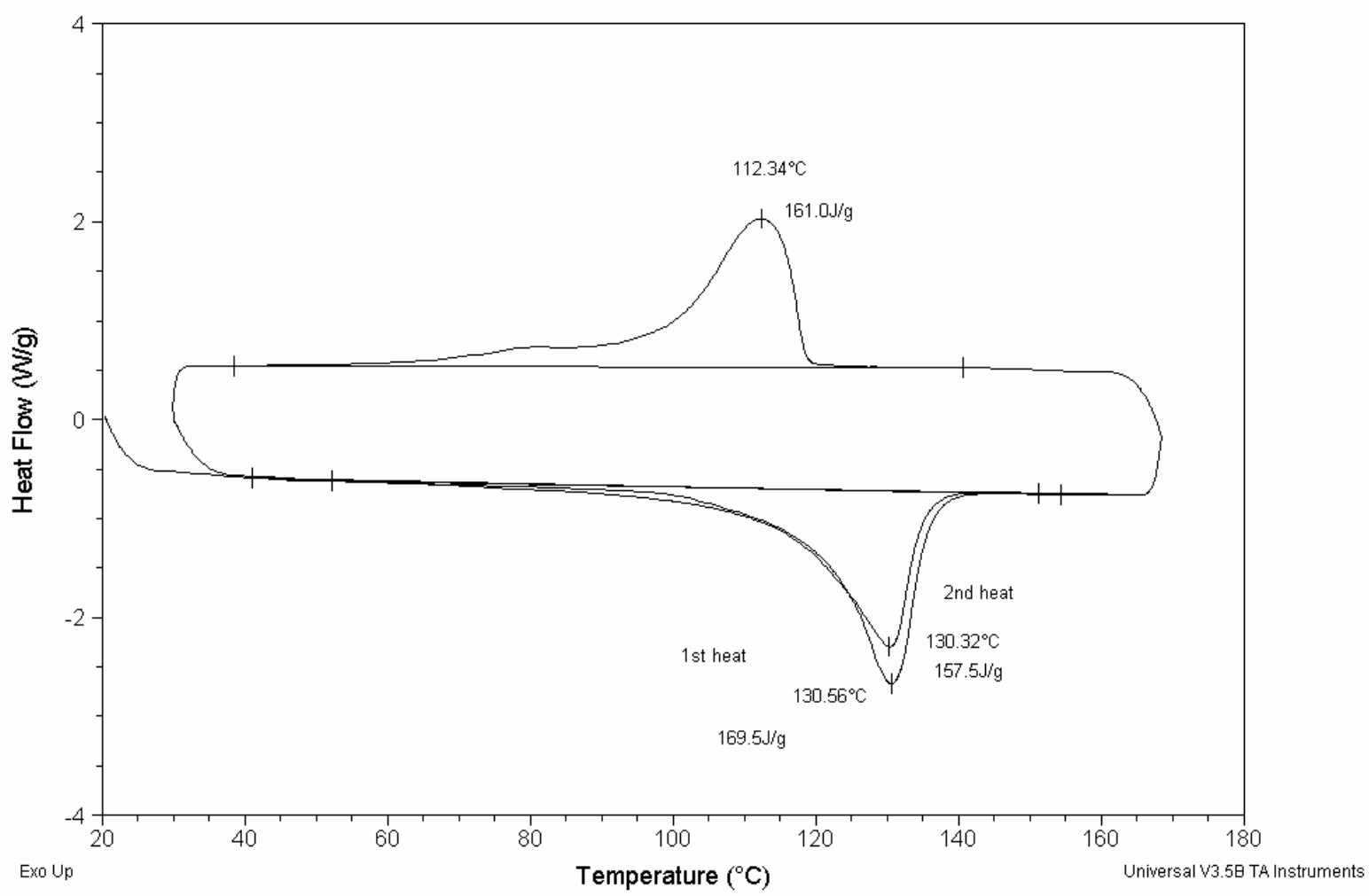

Fig. 4 


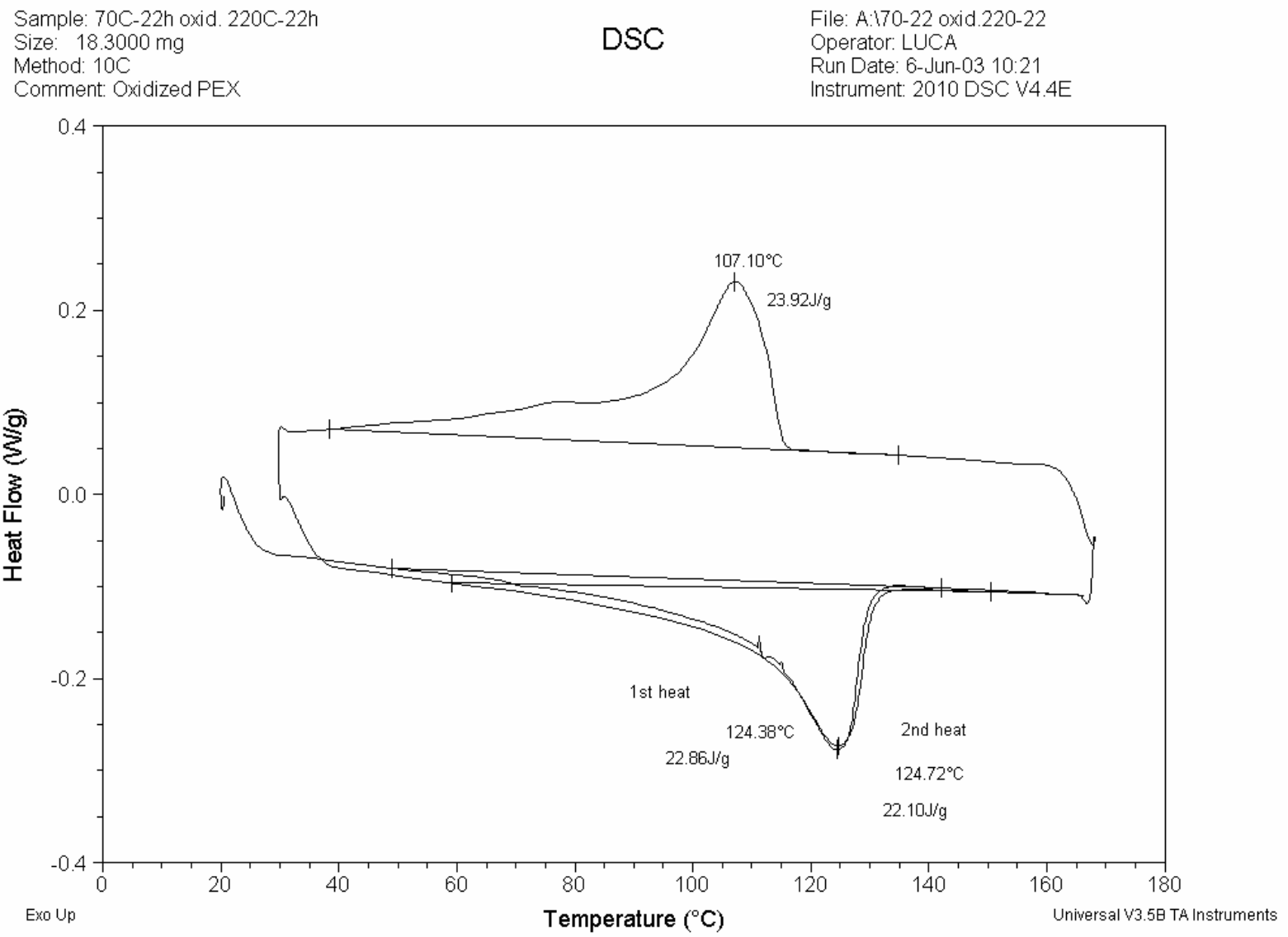

Fig. 5 


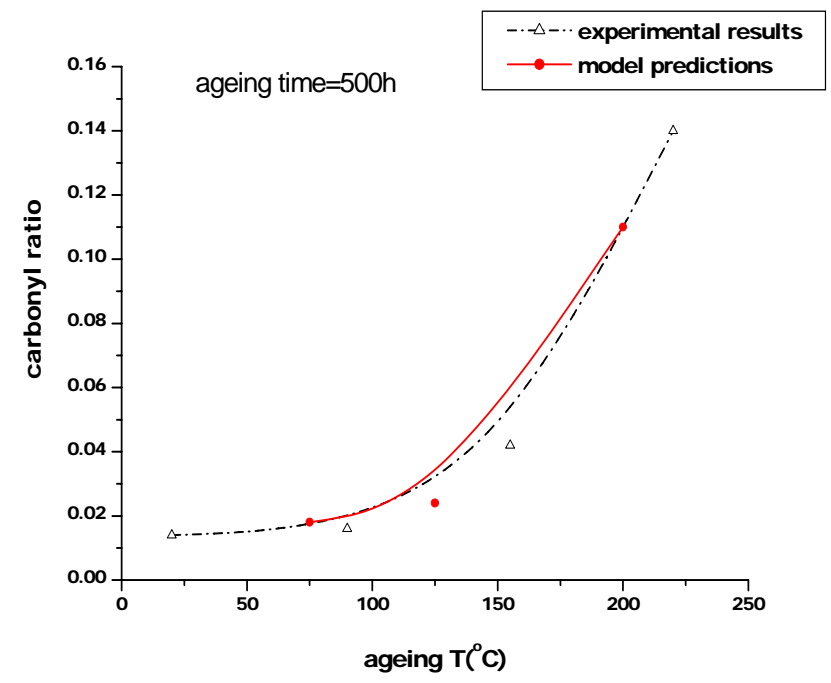

Fig. $6 a$

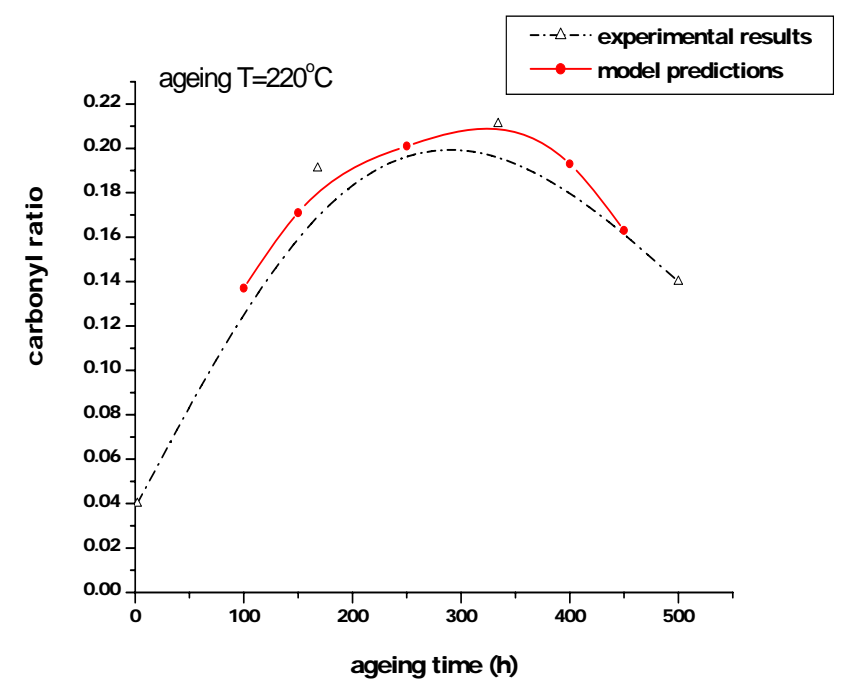


Fig. $6 b$

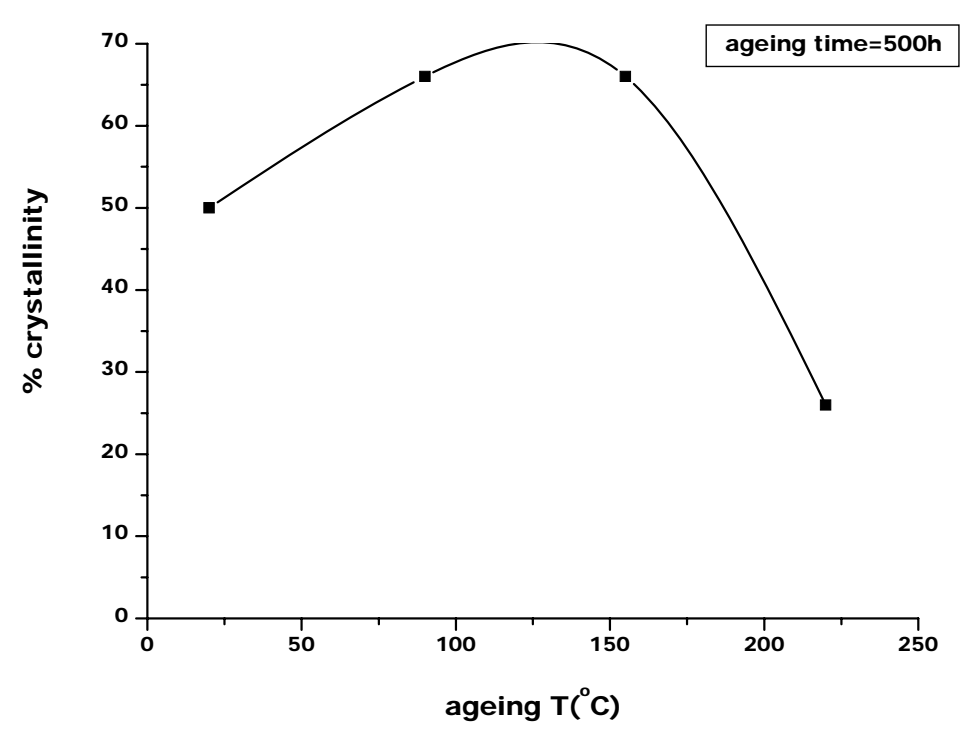

Fig. 7 


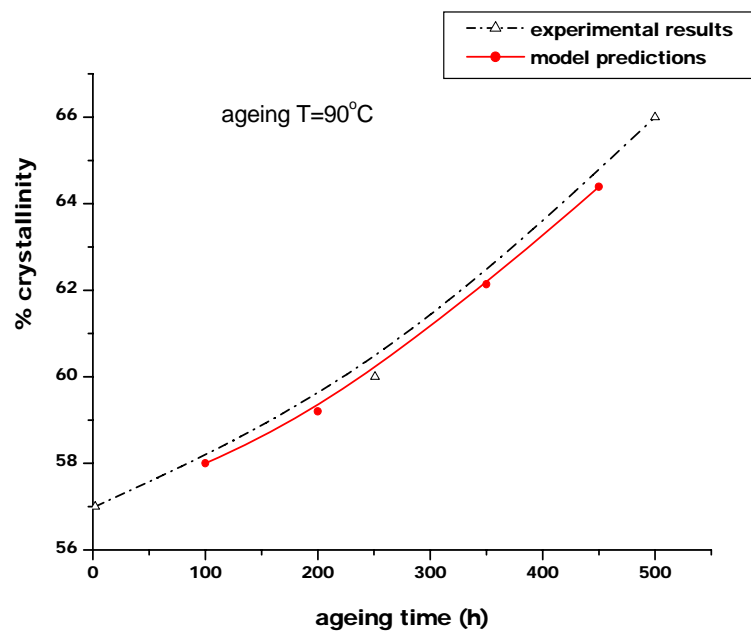

Fig.8a

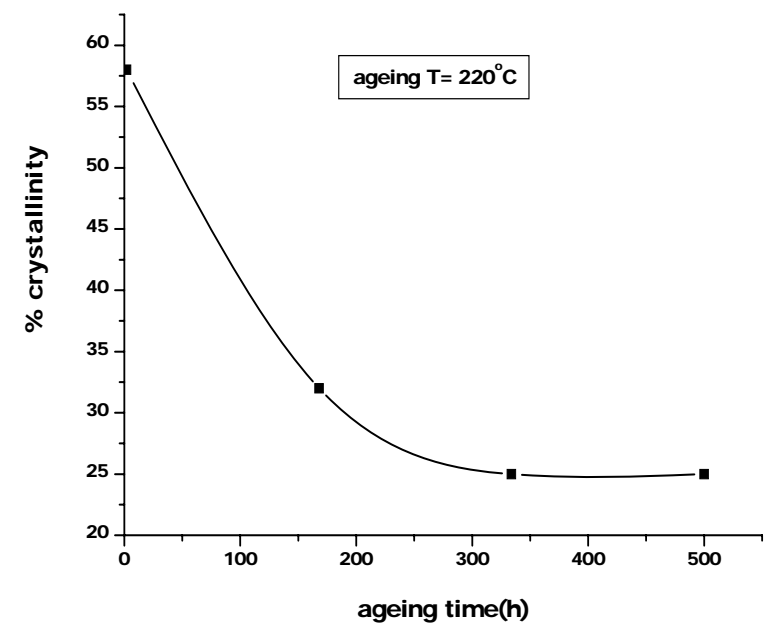

Fig.8b 


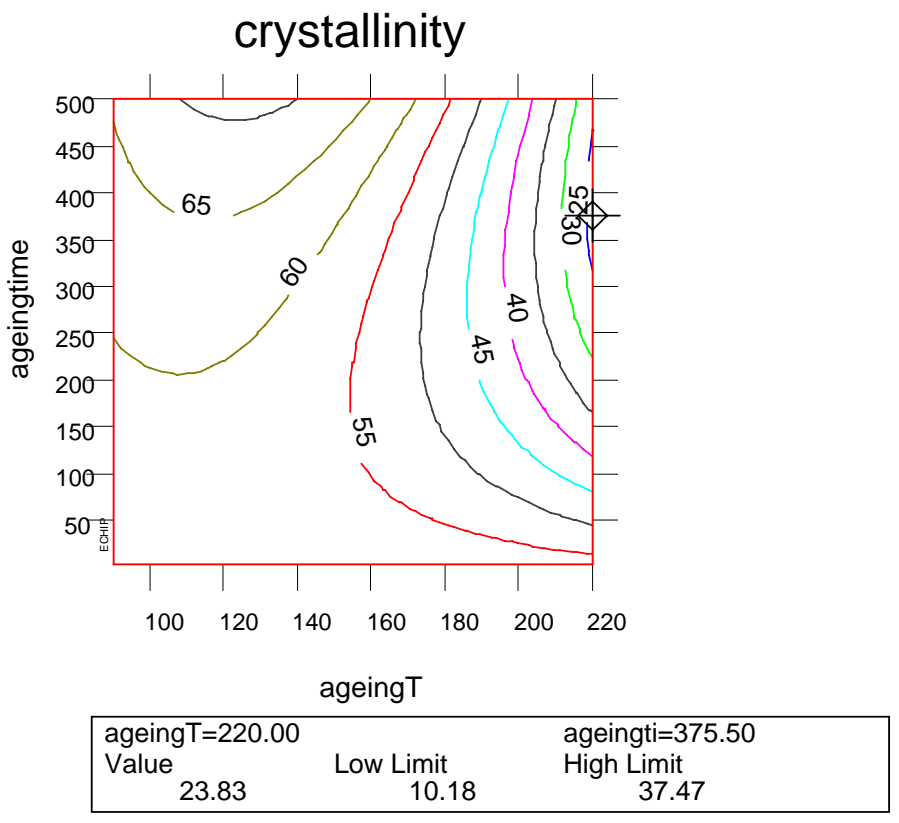

Fig. 9a

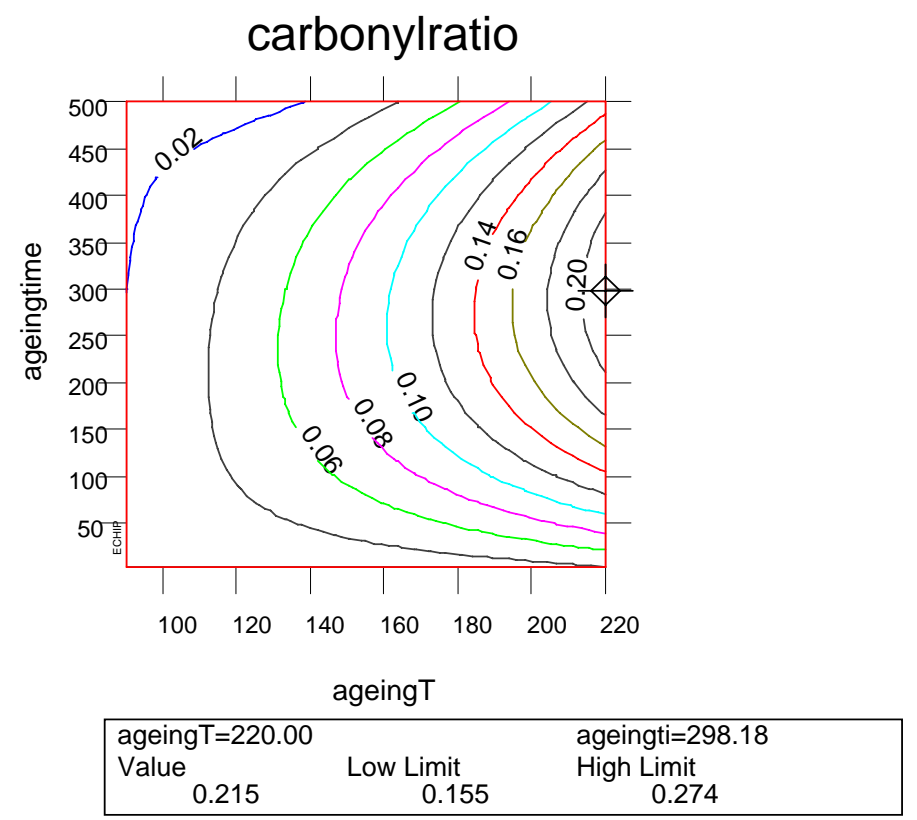

Fig. $9 b$ 


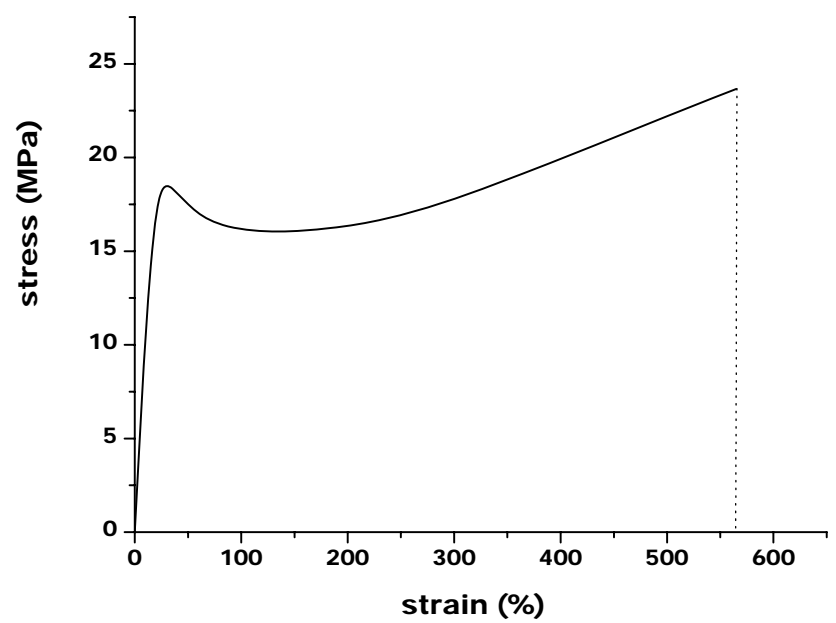

Fig. 10a

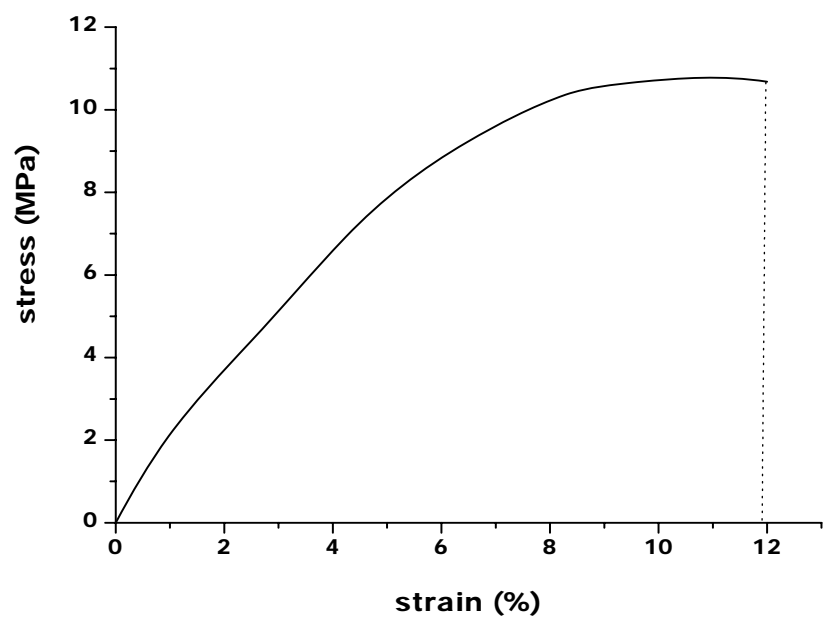

Fig. 10b 


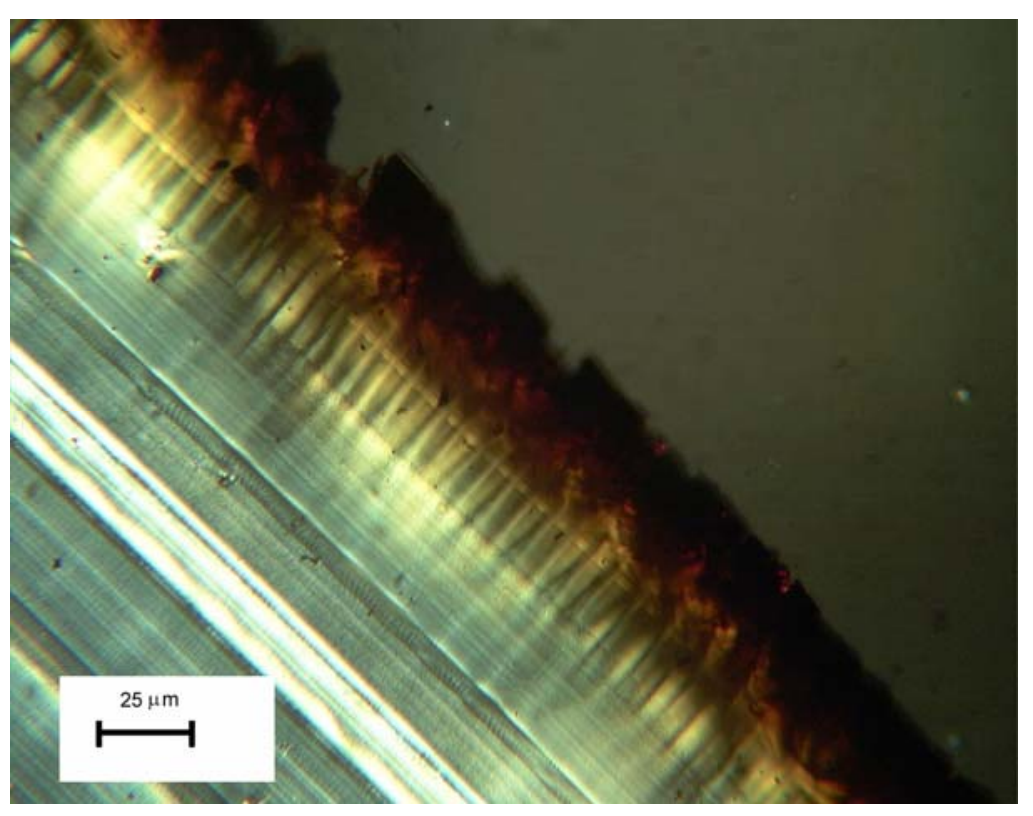

Fig. 11 